\title{
A practical guide to biomarkers for the evaluation of colorectal cancer
}

\author{
Wei Chen ${ }^{1} \cdot$ Wendy L. Frankel ${ }^{1}$
}

Received: 26 June 2018 / Accepted: 23 July 2018 / Published online: 2 January 2019

(c) United States \& Canadian Academy of Pathology 2019

\begin{abstract}
Evaluation of microsatellite instability (MSI) of every colorectal cancer (CRC) is important for prognostic and therapeutic purposes, while molecular testing helps identify actionable targeted therapy for patients with metastatic disease. This review will discuss the biomarkers commonly encountered in the clinical evaluation of CRC, and practical issues regarding MSI screening, reporting, interpretation, molecular test indication, and specimen requirements.
\end{abstract}

\section{Colorectal cancer and biomarkers for microsatellite instability/Lynch syndrome workup}

Colorectal cancer (CRC) is the third most common cancer among both men and women in the United States [1], with an estimated incidence of 135,430 new cases and 50,260 deaths in 2017 [2]. In the era of molecular classification of tumors, CRC has been grouped into four Consensus Molecular Subtypes (CMS) based on gene expression data and complex network analysis, reflecting significant biological differences between each subtype [3]. The biomarkers to be discussed in this review are the key classifiers for CRC CMS type 1 (microsatellite instability (MSI), BRAF mutation) and type 3 (mixed MSI status, KRAS mutation); and these two subtypes also represent the major clinically actionable types of CRC at this time.

Approximately $15 \%$ of CRC demonstrates MSI, a functional manifestation of mismatch repair (MMR) protein deficiency. Most MSI tumors are sporadic; however 2-4\% of CRC have MSI due to Lynch syndrome. Lynch syndrome is an autosomal-dominant hereditary cancer syndrome with germline mutation of MMR genes MLH1, PMS2, MSH2, MSH6, or EPCAM, with high penetrance. When a second hit knocks out the unaffected wild-type

Wendy L. Frankel

Wendy.Frankel@osumc.edu

1 Department of Pathology, The Ohio State University Wexner Medical Center, Columbus, OH, USA allele, cancer arises in Lynch syndrome patients. Enhanced cancer surveillance for these patients and their families saves lives by prevention, early detection, and treatment of cancer. In addition, awareness of MSI status of the tumor helps with risk stratification and guiding therapy selection for patients with CRC. Stage II patients with MSI tumor typically have a better prognosis than stage-matched microsatellite stable cancer [4-7] and do not benefit from 5-fluorouracil adjuvant therapy [8-10]; instead, they may benefit from PD-1 immune checkpoint blockade [11].

\section{Identification of MSI and Lynch syndrome patients}

The screening tools to identify Lynch syndrome patients have evolved dramatically, since Cancer Family Syndrome was first described by Henry Lynch in 1966 [12]. Amsterdam criteria were initially developed for research purposes in 1990 [13, 14]. They included a series of clinical criteria to help identify families likely to have Hereditary Nonpolyposis Colorectal Cancer (HNPCC) by using personal and family histories. The term HNPCC is no longer recommended since individuals with Lynch syndrome are also susceptible to develop non-colorectal neoplasms such as endometrium, stomach, small bowel, gallbladder, hepatobiliary tract, pancreas, renal pelvis/ureter, bladder, kidney, ovary, brain, and prostate, depending on the MMR gene involved and some patients can have polyps [12]. In general, patients with $M S H 2$ mutation are at increased risk of extra-colorectal neoplasms compared to patients with the more common MLHI mutation. Constitutional Mismatch 
Repair Deficiency syndrome (CMMR-D) patients may develop pediatric hematologic malignancies, brain tumors (glioblastoma), and neurofibromatosis type-1-like skin features [15]. Turcot syndrome, an allelic variant of CMMR-D, features multiple colorectal adenomas and brain cancer $[16,17]$. Muir-Torre syndrome, a rare variant of Lynch syndrome with $\mathrm{MSH} 2$ germline mutation, predisposes to hair follicle and sebaceous gland neoplasms [18]. Patients with germline mutations in MSH6 are more susceptible to the development of endometrial cancer. In 1997, Bethesda guidelines were developed to better identify high-risk patients needing tumor screening for Lynch syndrome [19]. In 2004, the Bethesda guidelines were revised to incorporate histomorphologic features of MSI tumors [20], including (1) tumor infiltrating lymphocytes, (2) Crohn'slike lymphocytic reaction, (3) mucinous/signet ring differentiation, and (4) medullary growth pattern [21-24]. The former two features are evidence of host immune response to the many tumor neoantigens in these hypermutated MSI tumors, a result of failure to repair DNA mismatches and accumulation of errors.

Histomorphology and family history (for Lynch syndrome) may help identify patients with MSI and Lynch syndrome, but using Amsterdam criteria and Revised Bethesda guidelines alone still miss many cases $[25,26]$. A study of 1066 CRC patients in metropolitan Columbus, Ohio, revealed that five (22\%) Lynch syndrome patients could have been missed using Amsterdam and Bethesda criteria alone, and 10 patients $(43 \%)$ were older than 50 years of age [26]. Furthermore, smaller family size than in the past and preventive polypectomy make personal and family history of cancer less useful in the recognition of Lynch syndrome patients.

In the past decade, tumor-based assays with MMR by immunohistochemistry (IHC) and MSI by polymerase chain reaction (PCR) have markedly increased the sensitivity ( $>90 \%)$ and specificity of Lynch syndrome screening [26-29]. Universal screening of CRC for Lynch syndrome has been recommended by many organizations, including the Evaluation of Genomic Applications in Practice and Prevention (a working group sponsored by the Centers for Disease Control and Prevention, 2009) [30], the National Comprehensive Cancer Network (2014) [31], the US MultiSociety Task Force (2014) [32], the American College of Gastroenterology, and the American Society of Clinical Oncology (2015) [33]. MMR IHC and/or MSI by PCR are now widely adopted as reliable and cost effective screening tools for MSI and Lynch syndrome workup [12, 34]. Since all patients with CRC are now recommended to undergo screening, the inclusion of histologic features suggesting MSI into pathology reports is less important than in the past. In fact, the College of American Pathologists no longer recommends the reporting of these histologic features in the current synoptic reporting template as of January 2018.

\section{DNA MMR proteins and IHC}

DNA MMR proteins are nuclear proteins that correct singlebase mismatches and insertion-deletion loops of short repeated nucleotide sequences that occur during DNA synthesis. In vivo, MLH1/PMS2 and MSH2/MSH6 form two functional pairs. If MLH1 or MSH2 is lost, its partner becomes unstable and will be degraded. However, the vice versa is not true, as the absence of PMS2 or MSH6 does not affect the stability of MLH1 and MSH2 since they can be stabilized by binding to other molecules [35].

MMR IHC enables visualization of the expression status of the four proteins within the nucleus. In general, the presence of all four proteins indicates microsatellite stable although exceptions exist (some cases with missense mutation may have retained staining); whereas staining loss indicates MMR deficiency with the pattern suggesting the defective gene. MMR screening is recommended using all four proteins, since the two- stain method (consisting of PMS2 and MSH6 only) may miss cases notwithstanding the cost saving [36]. The rational for the "two-stain" method is based on the heterodimer pairing of the MMR proteinsPMS2 and MSH6 should be lost regardless of whether there is a mutation in the gene encoding for them or their heterodimer partners (MLH1 and MSH2). MMR IHC is not considered genetic testing since it evaluates protein expression and can be seen with germline or somatic mutations or epigenetic events; however, abnormal staining patterns may suggest the most likely defective gene.

\section{Screening algorithm}

A suggested universal screening algorithm is shown in Fig. 1. All CRCs are stained with MMR IHC. If four proteins are all present, the CRC is considered microsatellite stable, as seen with the vast majority (85\%) of CRCs. No further workup is necessary unless there is clinical suspicion for Lynch syndrome or possibly in those patients younger than 50 years old. Among the remaining approximately $15 \%$ of cases that are MSI, the most common deficient pattern is the loss of MLH1/PMS2 with intact MSH2/MSH6 expression (Fig. 2 a-d). Most of the MLH1/PMS2-deficient cases represent sporadic tumors secondary to somatic MLH1 promoter hypermethylation (12\%) [37]; less cases are Lynch syndrome owing to germline $M L H 1$ mutation or constitutional hypermethylation of $M L H 1$ promoter $(<1 \%)$ [38, 39]. Therefore, MLHI promoter hypermethylation analysis of the tumor is a time- and cost-efficient test to detect patients with sporadic tumors who do not need additional testing. 


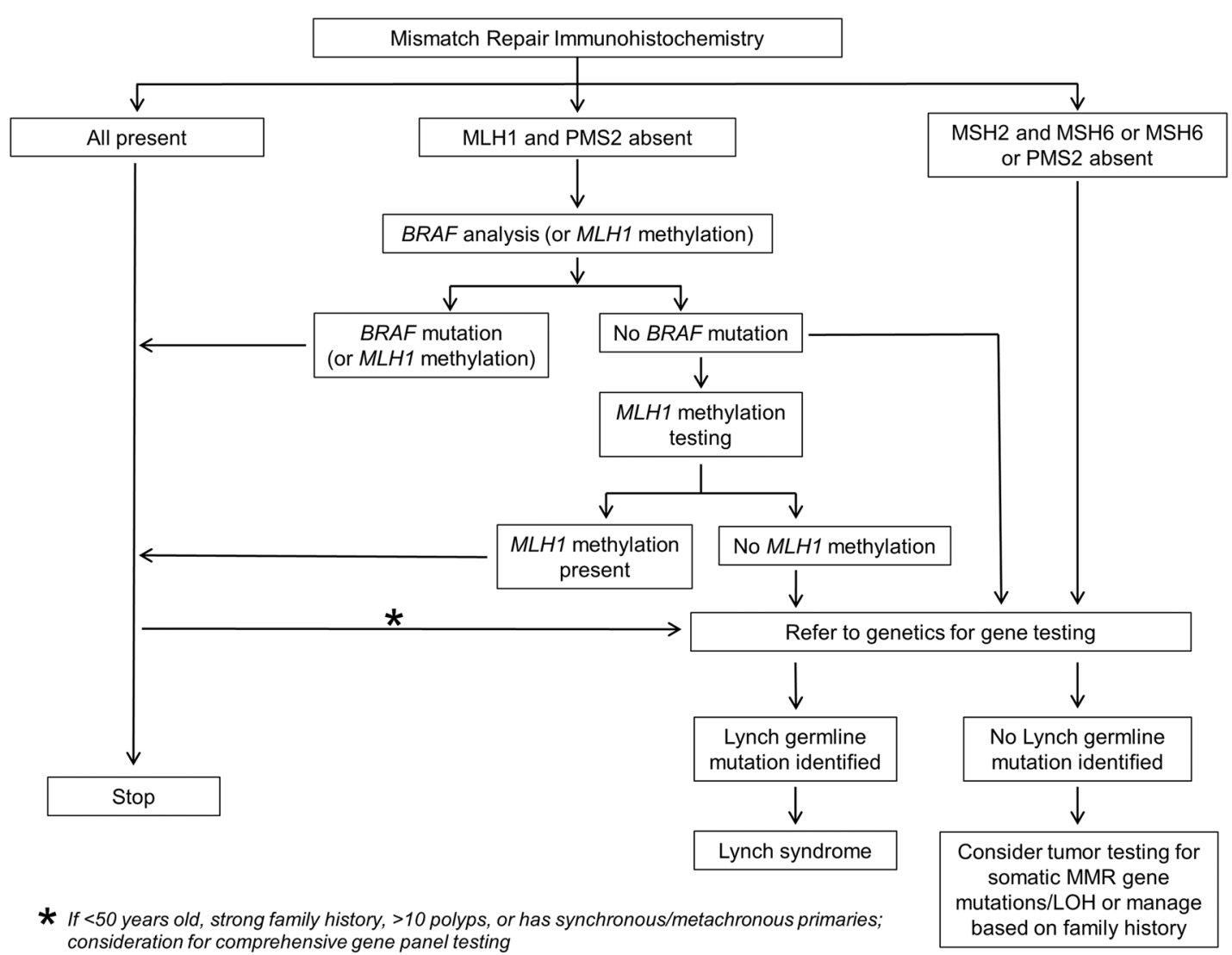

Fig. 1 Screening algorithm for mismatch repair deficiency and Lynch syndrome workup. All primary colorectal cancers (CRC) are immunostained for MLH1, MSH2, MSH6, and PMS2. The presence of all four proteins indicates intact expression and no further workup is necessary unless clinically suspicious. When MLH1 and PMS2 are absent, $B R A F$ V600E mutation analysis is performed. $B R A F$ mutation essentially excludes Lynch syndrome. If no $B R A F$ mutation is detected, the subsequent step depends on the degree of suspicion of Lynch syndrome based on the patient's age and history; if high suspicion, genetic sequencing of $M L H 1$ or PMS2 are done; if low suspicion, $M L H 1$ promoter hypermethylation is then analyzed. Non- $M L H 1$ hypermethylated cases undergo germline sequencing of $M L H 1$ or

Of note, hypermethylation of the $M L H 1$ promoter is often a manifestation of $\mathrm{CpG}$ island methylator phenotype (CIMP), which is the hypermethylation of multiple gene promoters. CRC with CIMP frequently harbors BRAF V600E mutations and methylation of $M L H 1$. In fact, greater than two-thirds of deficient MMR tumors are $B R A F$ mutated, and these tumors are most likely sporadic as $B R A F$ mutation is not associated with Lynch syndrome [40]. Many laboratories use BRAF mutational analysis rather than $M L H 1$ promoter methylation testing for MLH1/PMS2 absent tumors. However, if $B R A F$ is not mutated, $M L H I$ methylation testing may still be indicated since only about two-thirds methylated cases contain BRAF mutation [41, 42]. The presence of $B R A F$ mutation is also an adverse prognostic factor and may affect treatment decisions $[43,44]$. BRAF IHC is difficult to interpret due to staining
PMS2; those with methylation are presumed to represent sporadic tumors and Lynch workup is not indicated. Some laboratories use $M L H 1$ methylation testing rather than BRAF mutational analysis after immunohistochemistry in those tumors found to have absence of MLH1 and PMS2. Cases with absence of MSH2/MSH6, or isolated loss of MSH6, or isolated loss of PMS2, may represent Lynch syndrome and should undergo germline sequencing. Finally, if Lynch germline mutation is not identified in deficient MMR cases, tumor sequencing for double somatic mutation should be considered. In any patient diagnosed with CRC under the age of 50, a comprehensive germline panel should be considered

variability and $B R A F$ PCR is the preferred test [45]. If no $M L H 1$ promoter hypermethylation or BRAF V600E mutation is found, the patients should undergo germline gene testing after the patients receive genetic consultation.

The second most-common deficient IHC pattern is the loss of MSH2/MSH6 with intact MLH1/PMS2 (approximately 1\%) (Fig. 2e, h). Isolated PMS2 or MSH6 loss is less common and all these individuals have a probability for Lynch syndrome. They should undergo genetic consultation and germline gene sequencing.

When the etiology is not identified for MSI after $B R A F$ and/or methylation and germline mutation testing, sequencing of the tumor DNA for double somatic mutations of MMR genes should be considered. If double somatic mutations of MMR genes are found in the tumor without germline mutation in the blood, it confirms double somatic 
Fig. 2 Mismatch repair immunohistochemistry showing typical patterns of losses. The most common abnormal staining pattern-Loss of MLH1 (a) and PMS2 (b) with intact expression of MSH2 (c) and MSH6 (d). e-h The second most common abnormal staining patternintact expression of MLH1 (a) and PMS2 (b) with the loss of MSH2 (c) and MSH6 (d).

Notice the presence of staining in the background lymphocytes and stromal cells, which serve as positive internal control.

Original magnification $400 \times$

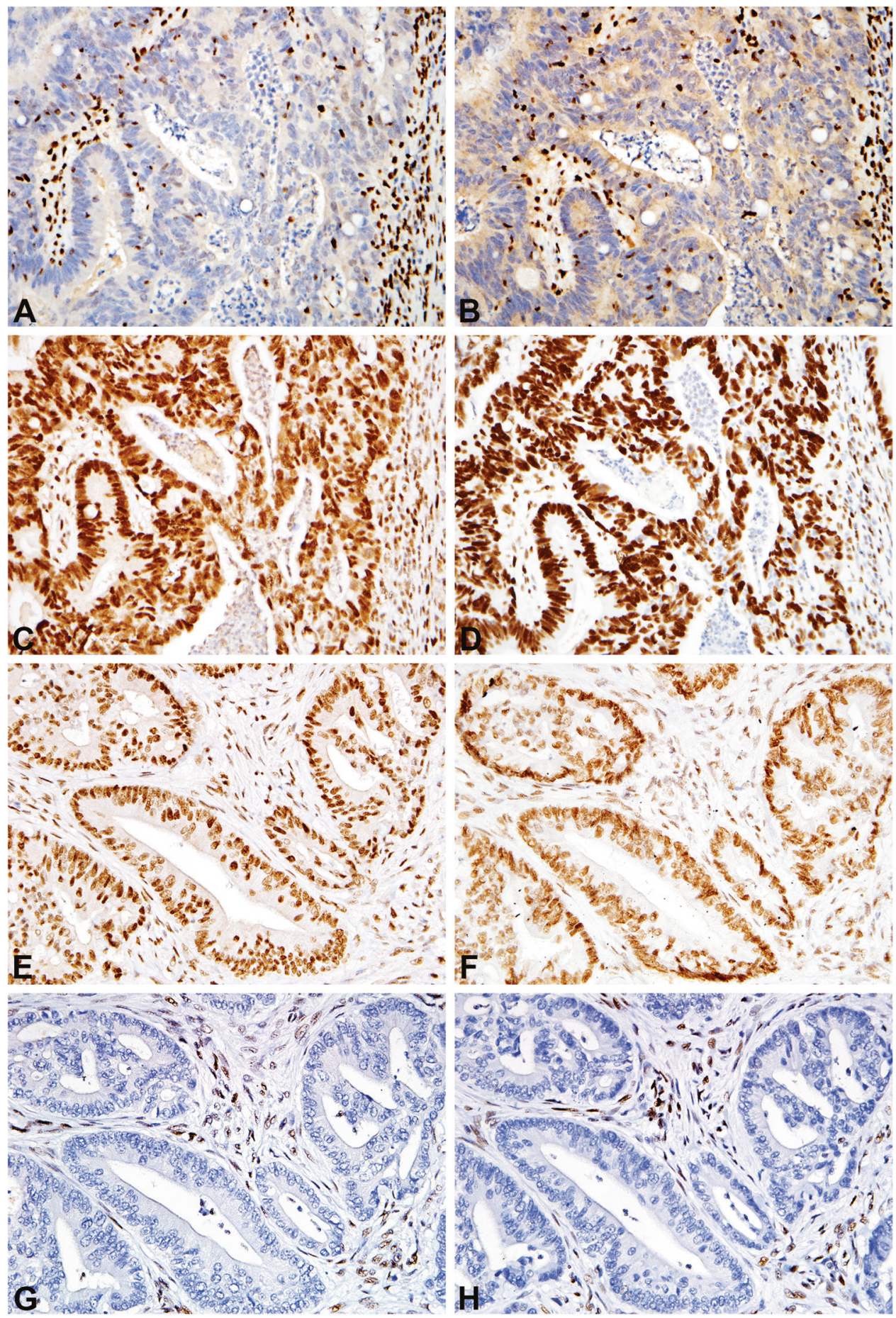

mutation as the cause of MSI. A double somatic mutation or a somatic mutation with loss of heterozygosity $(\mathrm{LOH})$ is the most common etiology for the so called Lynch-like syndrome (Fig. 3). Lynch-like syndrome is an umbrella term that has been used to describe these previously unexplained cases. The identification of the etiology as not germline is clinically very important since such patients and family do not need intensive lifelong screening for cancer [46].
Unfortunately, histologic findings are not useful to distinguish tumors with double somatic mutations from those occurring in the setting of Lynch syndrome, and sequencing of tumor is essential [47]. Other causes for Lynch-like phenomenon have also been identified [48, 49], including misinterpretation of immunohistochemical results (overcalling Lynch syndrome), germline alterations that are not detectable by current available tests, and other genetic 


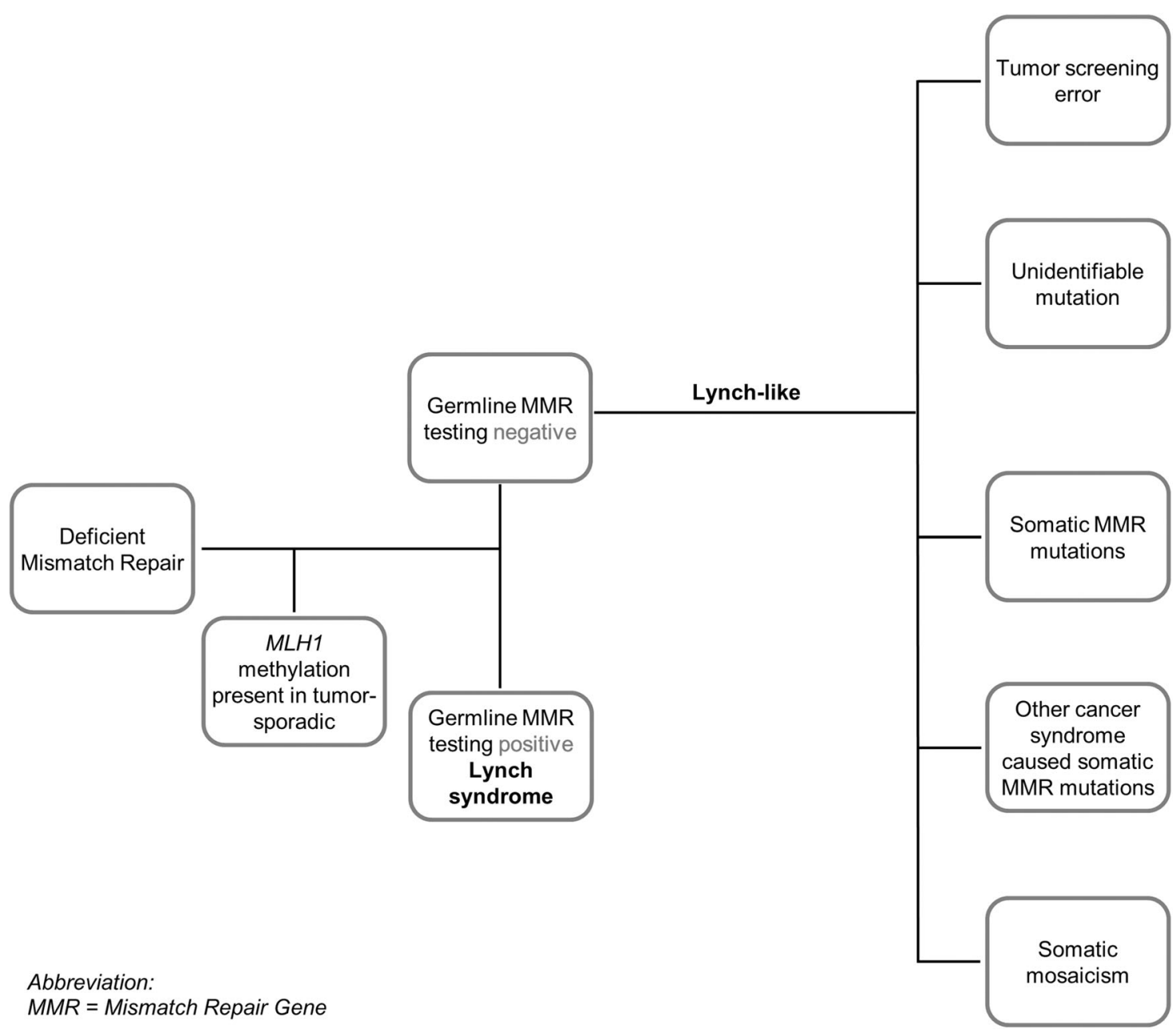

Fig. 3 Previously unexplained mismatch repair cases termed "Lynchlike". Mismatch repair deficient tumors without methylation, $B R A F$ mutation, or identified germline mutations have been referred to by the waste basket term "'Lynch-like". Possible causes include tumor

defects with MSI phenotype such as MUTYH mutation, POLE mutation, and somatic mosaicism.

\section{MSI by PCR}

An alternative screening test to MMR IHC is MSI testing, a molecular test in which microsatellite repeats of tumor DNA are examined by PCR. Several studies have shown that MSI by PCR demonstrates similar sensitivity and specificity as MMR IHC [27, 50, 51]. Using either test initially is reasonable in population screening. If microsatellite stability is found, but Lynch syndrome is strongly suspected, then the other test may be performed to obtain additional information. MMR IHC has the advantage of being more widely available with faster turnaround time, and no need for normal tissue. In addition, it can help direct screening error, unidentifiable mutation, somatic MMR mutations, other cancer syndrome causing somatic MMR mutations, and somatic mosaicism

gene testing by indicating the defective protein. In cases that have dense intratumoral inflammatory infiltrate, limited amount of tumor tissue, or unavailability of normal tissue (blood sample or normal colon) for comparison, MMR IHC is the preferred test.

The original MSI Bethesda panel [52] consists of five microsatellite repeats - two mononucleotide repeats (BAT25 and BAT26) and three dinucleotide repeats (D2S123, D5S346, and D17S250). Most laboratories now utilize mononucleotide-based tests, as more recent studies have demonstrated that mononucleotides are more sensitive and specific than dinucleotides [53, 54]. If a tumor demonstrates instability at $\geq 2$ examined loci, it is defined as MSI high. If a tumor exhibits instability at only one locus, it is MSI low. If there are no shifted microsatellites, the tumor is considered as microsatellite stable. 
Fig. 4 Typical and variant patterns of intact mismatch repair protein expression. Some variation of staining is allowed as shown and the internal control is the key to proper evaluation. a Typical staining (MSH6): tumor (lower half image) showing similar staining intensity as background control/ normal crypts (upper half image). b Expression in the tumor (MSH2, arrowheads) is stronger than background internal control (arrows). c Intratumoral patchiness/ uneven staining (MSH6). Original magnification $400 \times$

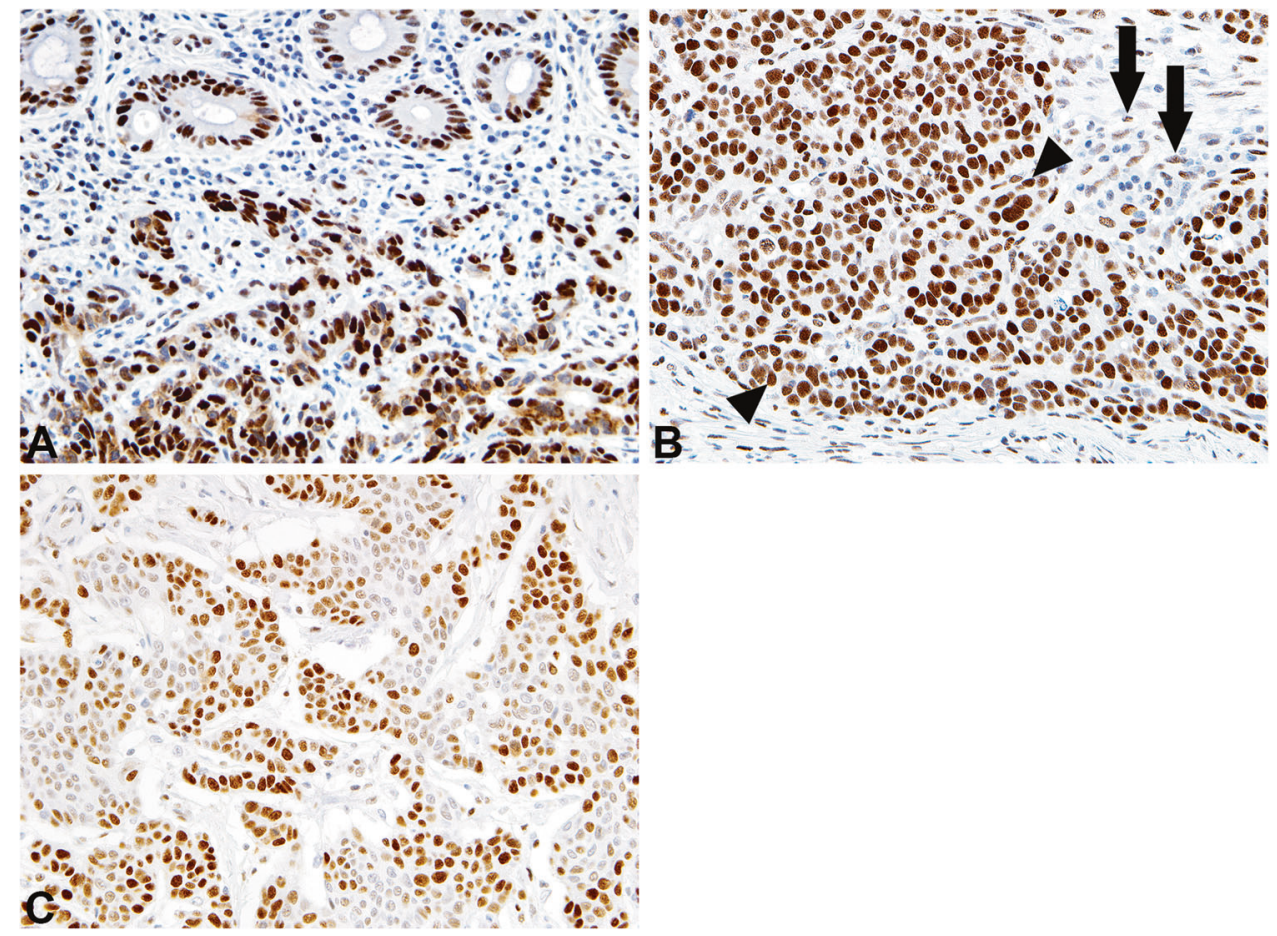

\section{IHC evaluation and reporting}

\section{Reporting terminology}

When reporting staining results of MMR protein IHC, the College of American Pathologists recommends using the term "intact or lost", instead of "positive or negative", to avoid confusion [55]. For example, "positive" could be misinterpreted as "positive for MMR deficiency" rather than "positive staining" (normal/intact staining pattern).

\section{Control is the key}

The key to the interpretation of MMR protein IHC is the same as that for any other immunohistochemical studythe control. MMR proteins function inside the nucleus of actively proliferating cells, as they correct the errors made during DNA synthesis. Therefore, nuclear staining of MMR proteins is expected to be present in any normal proliferating cells, such as lymphocytes, basal colonic crypt cells, and some stromal cells. Such cells serve as internal positive control when evaluating MMR protein IHC. Loss of tumor staining in areas without internal control staining is not interpretable, and the test needs to be repeated on the same or a different tumor block or another test (such as MSI) performed. One rare exception to this is constitutive MMR deficiency, in which both tumor and background normal tissue do not stain for MMR protein.

\section{Cutoff for normal staining}

No well-studied, evidence-based exact cutoff for normal MMR expression has been established. The College of American Pathologists endorses "any positive reaction in the nuclei of tumor cells" [55] and other authors suggest $1 \%, 5 \%$, or $10 \%$ as the cutoff [49]. In our practice, we use greater than $5 \%$ tumor nuclei demonstrating unequivocal nuclear staining (staining intensity at least similar to control).

\section{Staining variability/patchiness}

Typical intact MMR staining in CRC is diffuse, strong staining in most tumor nuclei (Fig. 4a, b). However, staining intensity may vary from case to case, as well as differ from area to area within each case (Fig. 4c). This variation in staining intensity is not uncommon, and the expression of MMR proteins is considered normal/intact if the staining in the tumor nuclei is equal to or stronger than the internal control cells. Factors such as antibody diffusion, fixation, and tissue hypoxia are thought to account for the staining variability $[56,57]$. Edge effect can also impact variability in staining.

\section{IHC interpretation pitfalls}

MMR IHC interpretation is typically straightforward, but challenges are occasionally encountered. Awareness of 
Fig. 5 Mismatch repair immunohistochemistry: interpretation challenges and pitfalls. a No staining in tumor and stroma-control failure; such stain cannot be interpreted. b Tumor nuclei (arrowheads) weaker than control (arrows) abnormal staining pattern; additional study warranted. c Cytoplasmic staining present (arrow) obscuring nucleiconsider repeat staining. d MSH6 showing weak to loss of tumor staining (arrowheads) in the setting of post neoadjuvant chemoradiation therapy-consider repeat on pretreatment biopsy. Notice background stromal cells (arrow) show intact staining. e and $\mathbf{f}$ MSH6 heterogenous staining secondary to $\mathrm{MLH1/}$ PMS2 mutation. Area of intact staining (left side of images) juxtaposed to area of staining loss (right side of images). Notice the background lymphocytes show intact staining (arrow) despite the loss of staining in tumor nuclei (arrowhead). Original magnification, a-d; f, 400x; e, $200 x$
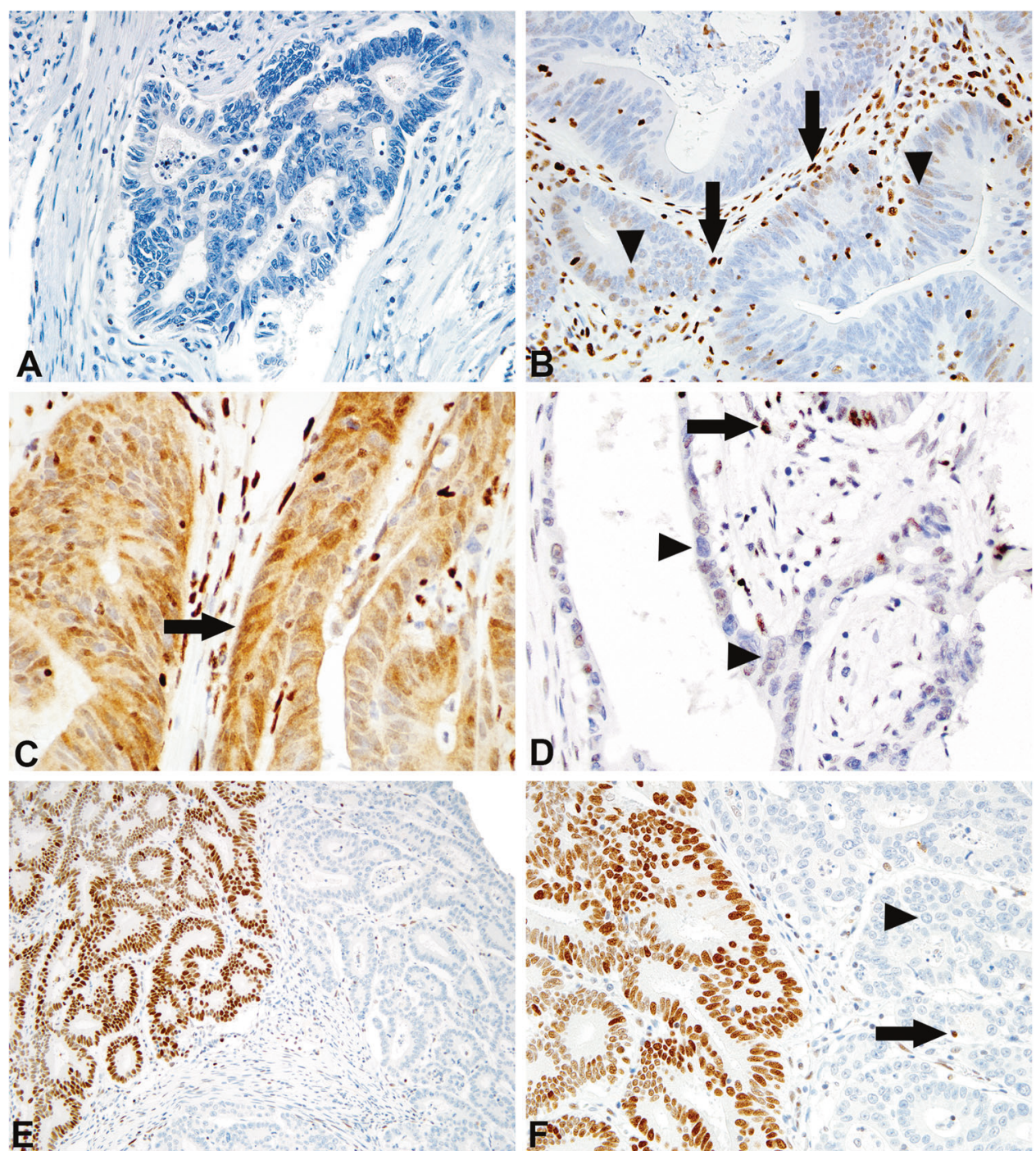

these pitfalls will help avoid errors in interpretation (Fig. 5 and Table 1) and are discussed below.

\section{Tumor weaker than control}

Some cases show focal faint nuclear staining that is weaker than the internal control cells. If such staining is confirmed on a repeat staining, the result should be interpreted as abnormal and additional studies are warranted. In our experience, some such cases are indeed MMR deficient.

\section{Cytoplasmic staining}

As discussed earlier, MMR protein staining is a nuclear stain and the presence of cytoplasmic only staining should be considered as an abnormal staining pattern. Recently, cytoplasmic MSH2 immunoreactivity has been reported in a Lynch syndrome patient with an EPCAM-MSH2 fusion
[58]. Occasionally, overstained microsatellite-stable tumor tissue may show both nuclear and cytoplasmic staining. Repeat staining may help to clarify whether the cytoplasmic staining is obscuring any nuclear staining or not.

\section{Post neoadjuvant therapy}

It is well documented that treated rectal cancer may show decreased or absent MMR protein expression, especially with MSH6 and PMS2 [59-62]. If this is encountered, repeat staining, if necessary, on a pre-treatment sample may be easier and less expensive than proceeding with molecular testing.

\section{MSH6 heterogenous staining}

Heterogenous MSH6 staining has been observed in CRC with MLH1/PMS2 deficiency due to somatic mutation of an 
Table 1 Mismatch repair protein immunohistochemistry interpretation pitfalls

\begin{tabular}{|c|c|c|}
\hline Staining pattern & Possible causes & Next steps \\
\hline $\begin{array}{l}\text { Both tumor \& internal control show lost/ } \\
\text { weak expression }\end{array}$ & $\begin{array}{l}\text { Poor fixation or antibody diffusion (if focal); } \\
\text { Technical issue with immunohistochemistry }\end{array}$ & $\begin{array}{l}\text { Repeat stain; Stain other block; MSI } \\
\text { by PCR }\end{array}$ \\
\hline Tumor weaker than control & Mismatch repair abnormality & $\begin{array}{l}\text { Repeat-Call equivocal or lost if still } \\
\text { the same; MSI by PCR }\end{array}$ \\
\hline $\begin{array}{l}\text { Post neoadjuvant therapy: nucleolar } \\
\text { staining, tumor weaker than control, or } \\
\text { patchy staining }\end{array}$ & $\begin{array}{l}\text { Post neoadjuvant therapy-related decreased MSH6 } \\
\text { (or PMS2) staining }\end{array}$ & Repeat on pre-treatment biopsy \\
\hline Cytoplasmic staining & $\begin{array}{l}\text { Technical issue with immunohistochemistry or } \\
\text { tissue; Mismatch repair abnormality such as in } \\
\text { EPCAM-MSH2 fusion }\end{array}$ & $\begin{array}{l}\text { Repeat; Stain other block; Call lost if } \\
\text { cytoplasmic staining only }\end{array}$ \\
\hline
\end{tabular}

unstable mononucleotide tract in MSH6 [63, 64]. Care should be taken to ensure that the control nuclei stain appropriately in areas with and without MSH6 expression. No germline mutations of MSH6 have been detected in such cases so far.

\section{Missense mutation with retained protein antigenicity}

About 3-10\% of Lynch syndrome cases have defective MMR protein expression resulting from missense mutations that cause structural/functional abnormalities. The protein retains its antibody-binding site for the immunohistochemical assay, and therefore masquerades with "normal" nuclear staining. This is most commonly seen in $M L H 1$ missense mutation cases with isolated loss of PMS2 staining (MLH1 staining retained despite dysfunctional MLH1 protein) [65, 66]. For this reason, the presence of MMR protein staining does not unequivocally exclude the possibility of finding a germline mutation/Lynch syndrome.

\section{Sample source selection}

Some samples are better than others for CRC biomarker testing. The advantages and disadvantages of various samples are discussed below.

\section{Biopsy vs. resection}

Studies have shown that biopsies work equally well as resection specimens for MMR IHC [67-69]. Occasional pitfalls in IHC interpretation occur in both types of samples. Edge effect may occur more often in small biopsy portions of tissue, while poor fixation and decreased antibody diffusion in the center of the tumor may occur with large sections from the resection specimen. We prefer to stain pre-operative biopsy specimens when they are available, since the results may alter the planned surgical procedure (segmental vs. subtotal colectomy). In addition, for rectal cancers, using pre-treatment biopsies avoids the sometimes difficult staining interpretation post treatment. Of note, if the testing is done on biopsy specimens, a clear communication program should be in place for patients who seek surgical resection at another institution to avoid concerns over the possible lack of follow-up testing if necessary.

\section{Metastasis vs. primary tumor}

For MMR protein testing, there is high concordance rate between primary and metastatic CRC [70]. For predictive molecular biomarker testing, metastatic/recurrent cancer sample is preferred for capturing the molecular evolution of the tumor [71].

\section{One vs. all tumors}

If a patient has more than one Lynch syndrome-related tumor, screening for MMR deficiency is recommended on all synchronous/metachronous tumors, since there is high discordant rate $(31 \%)$ [72]. Finding one tumor to be microsatellite stable does not exclude the possibility that another will be unstable. It is possible for a Lynch syndrome patient to have a sporadic neoplasm that is not due to a germline MMR gene defect. Once one tumor is identified as MSI, and the patient and possibly their germline is studied to support Lynch syndrome, additional screening may not be indicated.

\section{Adenoma vs. carcinoma}

Carcinoma is the preferred specimen for MSI screening; however, family member or previous patient CRC specimens may not always be available for testing, or a patient may have only adenomas. Therefore, clinicians may request testing on adenomas in patients with a suspicious family history for Lynch syndrome. In such situations, loss of MMR expression is helpful for ruling in Lynch syndrome, but intact MMR expression in adenomas does not exclude Lynch syndrome. Loss of MMR staining can be identified in 70-79\% Lynch-associated adenomas, especially in those with larger polyp size $(>10 \mathrm{~mm})$, villous component, or 
Table 2 Recommended specimens for molecular biomarker testing in colorectal cancer (CRC)

\begin{tabular}{ll}
\hline Sample type & $\begin{array}{l}\text { Recommended: formalin fixed paraffin embedded (FFPE) tissue [71] } \\
\text { Alternatives: cytology specimen (requires additional validation); Liquid biopsy } \\
\text { (serum or plasma) possibly in near future }\end{array}$ \\
Sample source & $\begin{array}{l}\text { Recommended: metastatic or recurrent tumor tissue preferred for targeted therapy } \\
\text { [71] }\end{array}$ \\
& Alternative: primary tumor tissue acceptable \\
& *Both primary and metastatic CRC OK for Lynch syndrome screening [70] \\
Minimum tissue & In general, assays require a minimum of 10-20\% tumor content (assuming LOD = \\
needed & 5\%); Ideally, 100-500 ng DNA (ten 5- $\mu$ m sections with $10 \mathrm{~mm} \times 10 \mathrm{~mm}$ area of \\
& tumor); As little as 10 ng DNA can work (about $2 \times 5$ mm needle core) [77] \\
Tumor enrichment & Tumor cores from FFPE block or tumor microdissection from cut sections (tumor \\
& marking by Pathologist-avoid necrosis/lymphoid tissue/adenoma /mucin/fat) \\
Turn-around time & $90 \%$ of specimens sent out for testing within three working days; 90\% of reports be \\
& available within 10 working days from the date of receipt in the molecular \\
laboratory [71]
\end{tabular}

high-grade dysplasia [73-76]. The presence of protein expression in an adenoma does not exclude the possibility of Lynch syndrome, since the adenoma may have not acquired the second mutation hit. We test adenomas by request and explain the pitfall.

\section{Serrated polyp vs. adenoma}

Serrated polyps are not typically precursor lesions for Lynch syndrome; therefore, they should not typically be tested for MMR deficiency to identify Lynch syndrome. Some serrated polyps with dysplasia may exhibit MMR deficiency due to $B R A F$ mutation, unrelated to Lynch syndrome. In contrast, adenomas can be precursor lesions for Lynch syndrome-related CRC, and may be tested with the caveat mentioned previously.

\section{Molecular biomarkers for targeted therapies for CRC}

Surgical pathologists play an important role in tissuebased DNA testing as curators of diagnostic tumor tissue. Prior to performing expensive molecular testing, pathologists must determine whether there is adequate tumor tissue for molecular analysis. This is typically not a major concern for CRC resection specimens as there is usually ample tumor tissue. For rectal cancer post neoadjuvant therapy with only rare and scattered residual tumor, a pretreatment biopsy may be more suitable for molecular testing. As a general rule, in small biopsies, at least $10-20 \%$ viable tumor is required for molecular testing [77] (Table 2).

Another important task for pathologists is to mark the tumor on the slides, so that microdissection can be performed when necessary for tumor DNA enrichment and extraction. Attention should be paid to marking areas with adequate viable tumor to ensure good-quality DNA for sequencing. It is best to avoid necrotic tissue (highly fragmented DNA), lymphocyte-rich area (may dilute tumor signal by high-density normal nuclei/DNA), adenomatous component (may lack all genetic abnormalities seen in cancer), and mucin/fatty areas if possible (Fig. 6).

A summary of the molecular biomarkers in the evaluation of CRC is shown in Table 3.

\section{Anti-EGFR therapy and extended RAS mutational analysis}

Many advanced CRC have uncontrolled cell growth and proliferation due to the activation of EGFR signaling pathway (EGFR-RAS-RAF-MEK-ERK/MAPK). AntiEGFR therapy employs monoclonal antibodies (such as cetuximab, panitumumab) to block the transmembrane EGFR at the beginning of the cell signaling pathway. The binding of these antibodies to EGFR hinders ligandinduced dimerization of the receptor and results in inhibition of the EGFR-MAPK pathway (Fig. 7). Anti-EGFR therapy is associated with a highly variable response rate, high cost (cetuximab $\$ 67,277$ per patient) [78], and toxicity in some (rash and diarrhea). Therefore, it is very important to target therapy to those most likely to respond. If the downstream $R A S$ is mutated and is constitutively turned on, blockage of the upstream EGFR is futile, and will unnecessarily expose patients who cannot respond to therapy. For these reasons, RAS mutational analysis serves as a predictive marker for anti-EGFRtherapy patients.

Approximately $90 \%$ of the KRAS mutations in CRCs are present in codons 12 and 13 and less frequently in codons 59, 61, 117, and 146. Activating mutations in any of these codons lead to constitutive activation of the EGFR-MAPK signaling pathway resulting in unregulated cell proliferation 
Fig. 6 Tumor marking for molecular testing. a Well-fixed, viable, and cellular tumor areas generally yield good-quality DNA for biomarker testing. b Do not mark necrotic areas. c Avoid tumor areas with intermixed lymphocytic aggregates. d Do not use paucicellular/mucin-rich tumor areas if possible. Original magnification $100 x$
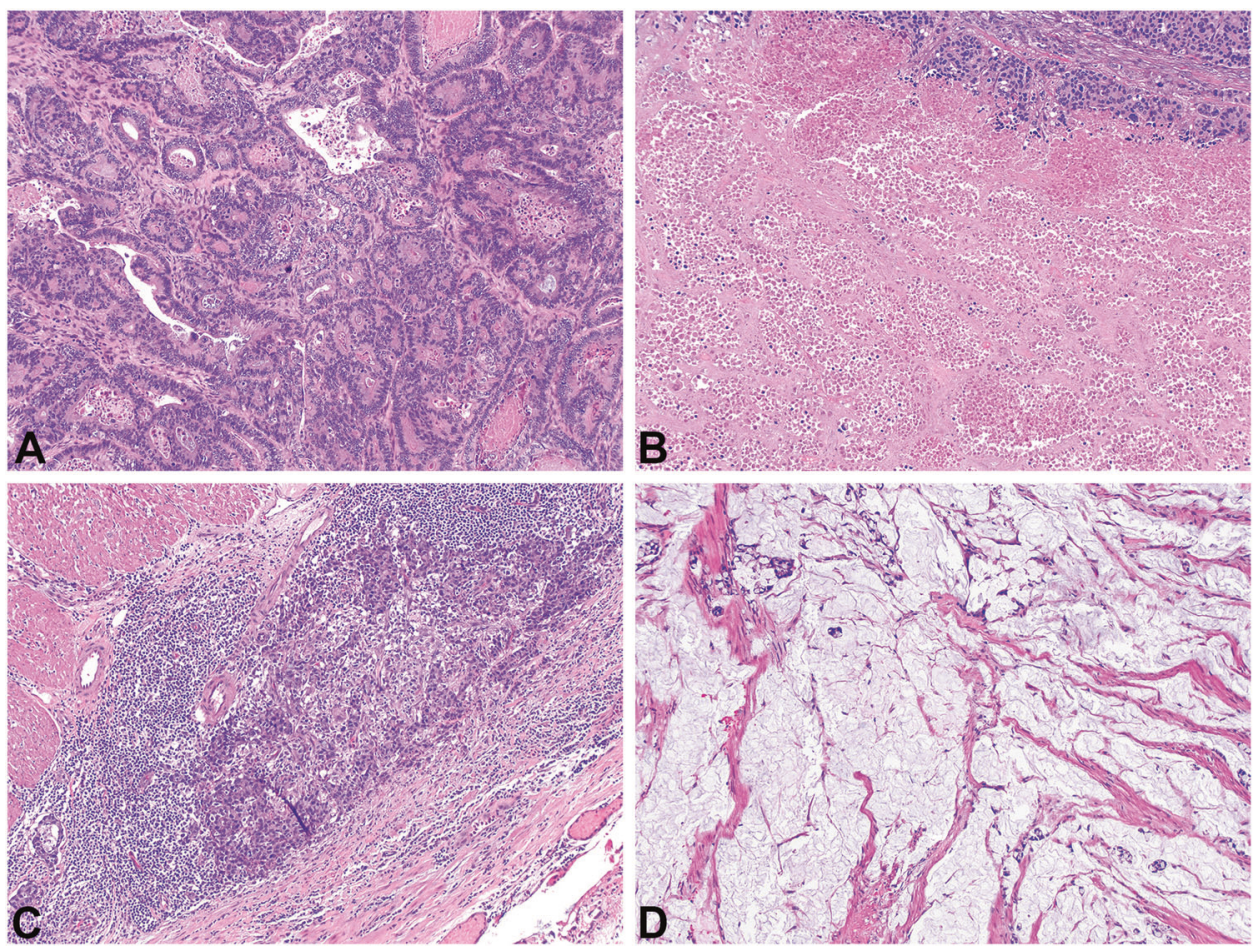

and resistance to anti-EGFR monoclonal antibody therapy [79]. In 2009, the American Society of Clinical Oncology (ASCO) recommended KRAS exon 2 analysis prior to antiEGFR therapy. Subsequently, it was discovered that $20 \%$ of exon 2 wild-type KRAS harbors another mutation in other codons of $K R A S$ or in NRAS, rendering resistance to antiEGFR therapy [80-83]. NCCN and ASCO guidelines now require that all candidates for anti-EGFR therapy undergo extended/expanded $R A S$ mutational analysis to identify $R A S$ mutated patients (approximately $40 \%$ of CRC) [71, 84]. The panel includes KRAS and NRAS codons 12 and 13 of exon 2, 59 and 61 of exon 3, and 117 and 146 of exon 4. Of note, even among patients with $R A S$ wild-type tumor, there is only $25-40 \%$ response rate.

$\boldsymbol{B R} \boldsymbol{A} \boldsymbol{F}$ V600E mutation is mutually exclusive with $K R A S$ mutations [85, 86]. Evidence suggests that mutations in $B R A F$ and other molecular targets downstream of EGFR contribute to the lack of treatment response [87, 88]. Specifically, studies indicate that BRAF V600E mutation makes response to panitumumab or cetuximab highly unlikely unless given together with a BRAF inhibitor [88-90]. However, insufficient data are present to justify excluding patients from $R A S$ wild-type/BRAF mutated tumors from anti-EGFR therapy at this time [71, 91].

\section{Emerging biomarkers}

Several biomarkers are undergoing additional evaluation and there is currently no recommendation for use, except in the setting of clinical trials. These include other molecules involved in EGFR axis modulation, such as PIK3CA, PTEN, and HER2 (Fig. 7).

PIK3CA is mutated in 10-18\% CRC. The PIK3CAAKT-mTOR pathway is located downstream of EGFR. Studies have shown that there is possibly improved survival in CRC patients with postoperative aspirin use if the CRC contains a PIK3CA mutation. Currently, there is insufficient data to deny anti-EGFR therapy to these patients based solely on the presence of PIK3CA mutation [71, 92].

PTEN, a PIK3CA inhibitor, is mutated in 5-14\% CRC. PTEN loss leads to upregulation of the PIK3A/AKT pathway and is associated with a lack of responsiveness to EGFR antagonists. PTEN mutation can be detected by loss of expression using IHC or deletion using FISH. Currently, there is insufficient data to deny anti-EGFR therapy to CRC patients based on PTEN mutation status [71, 92].

HER2 amplification and mutation are present in approximately $7 \%$ of CRCs. ErbB2/HER2 is a transmembrane receptor that belongs to the same ErbB receptor tyrosine kinase family as ErbB1/EGFR/HER1 (Fig. 7), and it has been investigated as a possible resistance pathway to anti-EGFR therapy in KRAS wild-type tumors [93]. Preliminary results from HERACLES trial indicate that dual HER2 blockade by trastuzumab (anti-HER2 antibody) and lapatinib (HER2 tyrosine kinase inhibitor) is well tolerated in treatment-refractory patients with HER2-positive metastatic CRC, with $30 \%$ patients showing objective response and 44\% showing stable disease [94]. Targeting HER2 


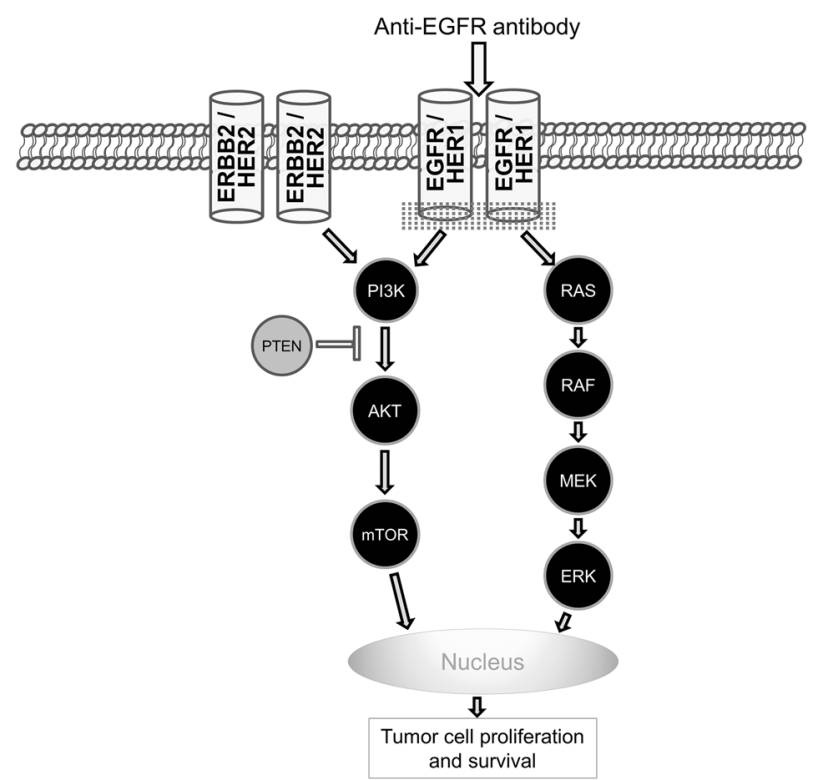

Fig. 7 Targeting the EGFR signaling pathway. Epidermal growth factor receptor (EGFR/HER1) is a transmembrane protein receptor of the ErbB family, which also includes HER2/ErbB-2. EGFR pathway is frequently activated in colorectal cancer, through downstream RAS/ MAPK and PI3K/AKT signaling pathways, leading to cell growth and proliferation. Anti-EGFR antibodies (such as cetuximab and panitumumab) bind to the extracellular domain of the EGFR preventing its activation. However, activating mutations of downstream modulators such as RAS, BRAF, PI3K, PTEN, or amplification/mutation of other ErbB receptors such as HER2 may confer resistance to anti-EGFR therapy

appears to be a promising development for CRC patients and additional studies are ongoing.

Sequencing using multigene panel has become clinically practical with the advent of next-generation sequencing (NGS). NGS allows simultaneous evaluation of multiple genes implicated in CRC including MMR genes and many others, and may provide clinical benefits in a cost-effective manner. In a recent study [95], upfront tumor sequencing alone has been shown to have better sensitivity (100\% vs. $\sim 90 \%$ ) and equal specificity ( $95 \%$ ) to evaluate MSI status, when compared to MMR IHC plus BRAF mutational analysis or MSI plus $B R A F$. In addition, there are added benefits of getting simultaneous assessment of $R A S$ and $B R A F$ status by NGS. Upfront tumor sequencing appears to be a simpler and possibly superior method for CRC evaluation and may represent the direction of future CRC testing. For CRC patients under the age of 50 or those with high suspicion for hereditary cancer syndromes (strong family history, greater than 10 polyps, or synchronous/metachronous primaries), germline testing using broad multigene panel encompassing MMR genes and other cancer susceptibility genes should be considered [96-98]. Of course, reimbursement and other important issues such as proper classification of variants of uncertain significance will need to be 
further investigated prior to widespread recommended use of NGS for screening.

Liquid biopsy refers to the detection of circulating tumor cells (CTC), tumor DNA fragments (cell-free DNA, cfDNA), or tumor mRNA in exosomes, in patients' sera or plasma [99-101]. These assays serve as promising, minimally invasive biomarkers that enable real-time monitoring of disease without additional repeat biopsies. They can be powerful predictive tools for disease recurrence, tumor molecular evolution, and the assessment of antineoplastic therapy. TP53 and RAS mutations, MSI or LOH, as well as DNA hypermethylation may be detected using this technique [99]. This area is on the cutting edge of technology and many studies are ongoing.

\section{Conclusions}

The implementation of these effective screening tools allows many more patients with deficient MMR tumors and Lynch syndrome to be identified, leading to proper disease risk stratification and optimal therapy for these patients. In addition, family members can be better counseled and possibly surveyed for hereditary cancer risks. The continued advancement of technology and cost reduction of molecular testing make it possible for MSI testing to be accomplished with a validated NGS panel, especially in patients with metastatic disease who require genotyping of $R A S$ and $B R A F$. Emerging evidence has shown that upfront tumor sequencing has many advantages and may replace the current multistep screening algorithm in the near future. Regardless of the results of laboratory testing, clinical suspicion for Lynch or other hereditary cancer syndromes remains an important factor in clinical decision making.

Acknowledgements The authors would like to thank Shawn Scully and Debbbie Knight for their assistance in image production.

\section{Compliance with ethical standards}

Conflict of interest The authors declare that they have no conflict of interest.

\section{References}

1. Siegel RL, Miller KD, Jemal A. Cancer Statistics, 2017. CA: a cancer journal for clinicians. 2017;67:7-30.

2. Siegel RL, Miller KD, Fedewa SA, Ahnen DJ, Meester RGS, Barzi A, et al. Colorectal cancer statistics, 2017. CA: a cancer journal for clinicians. 2017;67:177-93.

3. Guinney J, Dienstmann R, Wang X, de Reynies A, Schlicker A, Soneson C, et al. The consensus molecular subtypes of colorectal cancer. Nature medicine. 2015;21:1350-6.
4. Popat S, Hubner R, Houlston RS. Systematic review of microsatellite instability and colorectal cancer prognosis. J Clin Oncol. 2005;23:609-18.

5. Tejpar S, Saridaki Z, Delorenzi M, Bosman F, Roth AD. Microsatellite instability, prognosis and drug sensitivity of stage II and III colorectal cancer: more complexity to the puzzle. J Natl Cancer Inst. 2011;103:841-4.

6. Hutchins G, Southward K, Handley K, Magill L, Beaumont C, Stahlschmidt $J$, et al. Value of mismatch repair, KRAS, and BRAF mutations in predicting recurrence and benefits from chemotherapy in colorectal cancer. J Clin Oncol. 2011;29:1261-70.

7. Benatti P, Gafa R, Barana D, Marino M, Scarselli A, Pedroni M, et al. Microsatellite instability and colorectal cancer prognosis. Clin Cancer Res. 2005;11:8332-40.

8. Sargent DJ, Marsoni S, Monges G, Thibodeau SN, Labianca R, Hamilton SR, et al. Defective mismatch repair as a predictive marker for lack of efficacy of fluorouracil-based adjuvant therapy in colon cancer. J Clin Oncol. 2010;28:3219-26.

9. Ribic CM, Sargent DJ, Moore MJ, Thibodeau SN, French AJ, Goldberg RM, et al. Tumor microsatellite-instability status as a predictor of benefit from fluorouracil-based adjuvant chemotherapy for colon cancer. N Engl J Med. 2003;349:247-57.

10. Carethers JM, Smith EJ, Behling CA, Nguyen L, Tajima A, Doctolero RT, et al. Use of 5-fluorouracil and survival in patients with microsatellite-unstable colorectal cancer. Gastroenterology. 2004;126:394-401.

11. Le DT, Uram JN, Wang H, Bartlett BR, Kemberling H, Eyring $\mathrm{AD}$, et al. PD-1 Blockade in Tumors with Mismatch-Repair Deficiency. N Engl J Med. 2015;372:2509-20.

12. Lynch HT, Snyder CL, Shaw TG, Heinen CD, Hitchins MP. Milestones of Lynch syndrome: 1895-2015. Nat Rev Cancer. 2015;15:181-94.

13. Vasen HF, Mecklin JP, Khan PM, Lynch HT. The International Collaborative Group on Hereditary Non-Polyposis Colorectal Cancer (ICG-HNPCC). Dis Colon Rectum. 1991;34:424-5.

14. Vasen HF, Watson P, Mecklin JP, Lynch HT. New clinical criteria for hereditary nonpolyposis colorectal cancer (HNPCC, Lynch syndrome) proposed by the International Collaborative group on HNPCC. Gastroenterology. 1999;116:1453-6.

15. Aronson M, Gallinger S, Cohen Z, Cohen S, Dvir R, Elhasid R, et al. Gastrointestinal Findings in the Largest Series of Patients With Hereditary Biallelic Mismatch Repair Deficiency Syndrome: Report from the International Consortium. Am J Gastroenterol. 2016;111:275-84.

16. Hamilton SR, Liu B, Parsons RE, Papadopoulos N, Jen J, Powell $\mathrm{SM}$, et al. The molecular basis of Turcot's syndrome. N Engl J Med. 1995;332:839-47.

17. Turcot J, Despres JP, St Pierre F. Malignant tumors of the central nervous system associated with familial polyposis of the colon: report of two cases. Dis Colon Rectum. 1959;2:465-8.

18. Schwartz RA, Torre DP. The Muir-Torre syndrome: a 25-year retrospect. Journal of the American Academy of Dermatology. 1995;33:90-104.

19. Rodriguez-Bigas MA, Boland CR, Hamilton SR, Henson DE, Jass JR, Khan PM, et al. A National Cancer Institute Workshop on Hereditary Nonpolyposis Colorectal Cancer Syndrome: meeting highlights and Bethesda guidelines. J Natl Cancer Inst. 1997;89:1758-62.

20. Umar A, Boland CR, Terdiman JP, Syngal S, de la Chapelle A, Ruschoff J, et al. Revised Bethesda Guidelines for hereditary nonpolyposis colorectal cancer (Lynch syndrome) and microsatellite instability. J Natl Cancer Inst. 2004;96:261-8.

21. Shia J, Holck S, Depetris G, Greenson JK, Klimstra DS. Lynch syndrome-associated neoplasms: a discussion on histopathology and immunohistochemistry. Fam Cancer. 2013;12:241-60. 
22. Smyrk TC, Watson P, Kaul K, Lynch HT. Tumor-infiltrating lymphocytes are a marker for microsatellite instability in colorectal carcinoma. Cancer. 2001;91:2417-22.

23. Jass JR, Smyrk TC, Stewart SM, Lane MR, Lanspa SJ, Lynch HT. Pathology of hereditary non-polyposis colorectal cancer. Anticancer Res. 1994;14:1631-4.

24. Yearsley M, Hampel H, Lehman A, Nakagawa H, de la Chapelle A, Frankel WL. Histologic features distinguish microsatellite-high from microsatellite-low and microsatellitestable colorectal carcinomas, but do not differentiate germline mutations from methylation of the MLH1 promoter. Hum Pathol. 2006;37:831-8.

25. Moreira L, Balaguer F, Lindor N, de la Chapelle A, Hampel H, Aaltonen LA, et al. Identification of Lynch syndrome among patients with colorectal cancer. JAMA. 2012;308:1555-65.

26. Hampel H, Frankel WL, Martin E, Arnold M, Khanduja K, Kuebler P, et al. Screening for the Lynch syndrome (hereditary nonpolyposis colorectal cancer). N Engl J Med. 2005; 352:1851-60.

27. Lindor NM, Burgart LJ, Leontovich O, Goldberg RM, Cunningham JM, Sargent DJ, et al. Immunohistochemistry versus microsatellite instability testing in phenotyping colorectal tumors. J Clin Oncol. 2002;20:1043-8.

28. de Jong AE, van Puijenbroek M, Hendriks Y, Tops C, Wijnen J, Ausems MG, et al. Microsatellite instability, immunohistochemistry, and additional PMS2 staining in suspected hereditary nonpolyposis colorectal cancer. Clin Cancer Res. 2004;10:972-80.

29. Southey MC, Jenkins MA, Mead L, Whitty J, Trivett M, Tesoriero AA, et al. Use of molecular tumor characteristics to prioritize mismatch repair gene testing in early-onset colorectal cancer. J Clin Oncol. 2005;23:6524-32.

30. Evaluation of Genomic Applications in Practice and Prevention (EGAPP) Working Group.. Recommendations from the EGAPP Working Group: genetic testing strategies in newly diagnosed individuals with colorectal cancer aimed at reducing morbidity and mortality from Lynch syndrome in relatives. Genet Med. 2009;11:35-41.

31. Hampel H. NCCN increases the emphasis on genetic/familial high-risk assessment in colorectal cancer. J Natl Compr Canc Netw. 2014;12:829-31.

32. Giardiello FM, Allen JI, Axilbund JE, Boland CR, Burke CA, Burt RW, et al. Guidelines on genetic evaluation and management of Lynch syndrome: a consensus statement by the US Multi-Society Task Force on colorectal cancer. Gastroenterology. 2014;147:502-26.

33. Syngal S, Brand RE, Church JM, Giardiello FM, Hampel HL, Burt RW. ACG clinical guideline: Genetic testing and management of hereditary gastrointestinal cancer syndromes. Am J Gastroenterol. 2015;110:223-62. quiz 63

34. Hampel H, Frankel WL, Martin E, Arnold M, Khanduja K, Kuebler P, et al. Feasibility of screening for Lynch syndrome among patients with colorectal cancer. J Clin Oncol. 2008;26:5783-8.

35. Li G-M. Mechanisms and functions of DNA mismatch repair. Cell Research. 2007;18:85.

36. Pearlman R MM, Knight D, Chen W, Arnold C, Pritchard C, Hampel H, Frankel W. Two-stain immunohistochemical screening for Lynch syndrome in colorectal cancer may fail to detect mismatch repair deficiency. Mod Pathol 2018; In Press.

37. Boland CR, Goel A. Microsatellite instability in colorectal cancer. Gastroenterology. 2010;138:2073-87 e3.

38. Rahner N, Friedrichs N, Steinke V, Aretz S, Friedl W, Buettner R, et al. Coexisting somatic promoter hypermethylation and pathogenic MLH1 germline mutation in Lynch syndrome. J Pathol. 2008;214:10-6.
39. Niessen RC, Hofstra RM, Westers H, Ligtenberg MJ, Kooi K, Jager PO, et al. Germline hypermethylation of MLH1 and EPCAM deletions are a frequent cause of Lynch syndrome. Genes Chromosomes Cancer. 2009;48:737-44.

40. Weisenberger DJ, Siegmund KD, Campan M, Young J, Long TI, Faasse MA, et al. CpG island methylator phenotype underlies sporadic microsatellite instability and is tightly associated with BRAF mutation in colorectal cancer. Nat Genet. 2006; 38:787-93.

41. Parsons MT, Buchanan DD, Thompson B, Young JP, Spurdle AB. Correlation of tumour BRAF mutations and MLH1 methylation with germline mismatch repair (MMR) gene mutation status: a literature review assessing utility of tumour features for MMR variant classification. J Med Genet. 2012;49:151-7.

42. Adar T, Rodgers LH, Shannon KM, Yoshida M, Ma T, Mattia A, et al. A tailored approach to BRAF and MLH1 methylation testing in a universal screening program for Lynch syndrome. Mod Pathol. 2017;30:440-7.

43. Yuan ZX, Wang XY, Qin QY, Chen DF, Zhong QH, Wang L, et al. The prognostic role of BRAF mutation in metastatic colorectal cancer receiving anti-EGFR monoclonal antibodies: a metaanalysis. PLoS One. 2013;8:e65995.

44. Roth AD, Tejpar S, Delorenzi M, Yan P, Fiocca R, Klingbiel D, et al. Prognostic role of KRAS and BRAF in stage II and III resected colon cancer: results of the translational study on the PETACC-3, EORTC 40993, SAKK 60-00 trial. J Clin Oncol. 2010;28:466-74.

45. Bellizzi AM. Screening for Lynch syndrome: a no-brainer: BRAF V600E mutation-specific immunohistochemistry: caveat emptor. Am J Clin Pathol. 2015;143:320-4.

46. Haraldsdottir S, Hampel H, Tomsic J, Frankel WL, Pearlman R, de la Chapelle A, et al. Colon and endometrial cancers with mismatch repair deficiency can arise from somatic, rather than germline, mutations. Gastroenterology. 2014;147:1308-16 e1.

47. Hemminger JA, Pearlman R, Haraldsdottir S, Knight D, Jonasson JG, Pritchard CC, et al. Histology of colorectal adenocarcinoma with double somatic mismatch repair mutations is indistinguishable from those caused by lynch syndrome. Hum Pathol 2018.

48. Chen W, Swanson BJ, Frankel WL. Molecular genetics of microsatellite-unstable colorectal cancer for pathologists. Diagnostic pathology. 2017;12:24.

49. Pai RK, Pai RK. A Practical Approach to the Evaluation of Gastrointestinal Tract Carcinomas for Lynch Syndrome. Am J Surg Pathol. 2016;40:e17-34.

50. Shia J. Immunohistochemistry versus microsatellite instability testing for screening colorectal cancer patients at risk for hereditary nonpolyposis colorectal cancer syndrome. Part I. The utility of immunohistochemistry. J Mol Diagn. 2008;10: 293-300.

51. Zhang L. Immunohistochemistry versus microsatellite instability testing for screening colorectal cancer patients at risk for hereditary nonpolyposis colorectal cancer syndrome. Part II. The utility of microsatellite instability testing. J Mol Diagn. 2008;10:301-7.

52. Boland CR, Thibodeau SN, Hamilton SR, Sidransky D, Eshleman JR, Burt RW, et al. A National Cancer Institute Workshop on Microsatellite Instability for cancer detection and familial predisposition: development of international criteria for the determination of microsatellite instability in colorectal cancer. Cancer Res. 1998;58:5248-57.

53. Buhard O, Suraweera N, Lectard A, Duval A, Hamelin R. Quasimonomorphic mononucleotide repeats for high-level microsatellite instability analysis. Disease markers. 2004; 20:251-7. 
54. Xicola RM, Llor X, Pons E, Castells A, Alenda C, Pinol V, et al. Performance of different microsatellite marker panels for detection of mismatch repair-deficient colorectal tumors. J Natl Cancer Inst. 2007;99:244-52.

55. Bartley AN, Hamilton SR, Alsabeh R, Ambinder EP, Berman M, Collins E, et al. Template for reporting results of biomarker testing of specimens from patients with carcinoma of the colon and rectum. Arch Pathol Lab Med. 2014;138:166-70.

56. Chang CL, Marra G, Chauhan DP, Ha HT, Chang DK, Ricciardiello L, et al. Oxidative stress inactivates the human DNA mismatch repair system. Am J Physiol Cell Physiol. 2002;283: C148-54.

57. Mihaylova VT, Bindra RS, Yuan J, Campisi D, Narayanan L, Jensen R, et al. Decreased expression of the DNA mismatch repair gene Mlh1 under hypoxic stress in mammalian cells. Mol Cell Biol. 2003;23:3265-73.

58. Sekine S, Ogawa R, Saito S, Ushiama M, Shida D, Nakajima T, et al. Cytoplasmic MSH2 immunoreactivity in a patient with Lynch syndrome with an EPCAM-MSH2 fusion. Histopathology. 2017;70:664-9.

59. Bao F, Panarelli NC, Rennert H, Sherr DL, Yantiss RK. Neoadjuvant therapy induces loss of MSH6 expression in colorectal carcinoma. Am J Surg Pathol. 2010;34:1798-804.

60. Radu OM, Nikiforova MN, Farkas LM, Krasinskas AM. Challenging cases encountered in colorectal cancer screening for Lynch syndrome reveal novel findings: nucleolar MSH6 staining and impact of prior chemoradiation therapy. Hum Pathol. 2011;42:1247-58.

61. Vilkin A, Halpern M, Morgenstern S, Brazovski E, GingoldBelfer R, Boltin D, et al. How reliable is immunohistochemical staining for DNA mismatch repair proteins performed after neoadjuvant chemoradiation? Hum Pathol. 2014;45: 2029-36.

62. Kuan SF, Ren B, Brand R, Dudley B, Pai RK. Neoadjuvant therapy in microsatellite-stable colorectal carcinoma induces concomitant loss of MSH6 and Ki-67 expression. Hum Pathol. 2017;63:33-9.

63. Graham RP, Kerr SE, Butz ML, Thibodeau SN, Halling KC, Smyrk TC, et al. Heterogenous MSH6 loss is a result of microsatellite instability within MSH6 and occurs in sporadic and hereditary colorectal and endometrial carcinomas. Am J Surg Pathol. 2015;39:1370-6.

64. Shia J, Zhang L, Shike M, Guo M, Stadler Z, Xiong X, et al. Secondary mutation in a coding mononucleotide tract in MSH6 causes loss of immunoexpression of MSH6 in colorectal carcinomas with MLH1/PMS2 deficiency. Mod Pathol. 2013;26:131-8.

65. Dudley B, Brand RE, Thull D, Bahary N, Nikiforova MN, Pai RK. Germline MLH1 Mutations Are Frequently Identified in Lynch Syndrome Patients With Colorectal and Endometrial Carcinoma Demonstrating Isolated Loss of PMS2 Immunohistochemical Expression. Am J Surg Pathol. 2015;39:1114-20.

66. Rosty C, Clendenning M, Walsh MD, Eriksen SV, Southey MC, Winship IM, et al. Germline mutations in PMS2 and MLH1 in individuals with solitary loss of PMS2 expression in colorectal carcinomas from the Colon Cancer Family Registry Cohort. BMJ Open. 2016;6:e010293.

67. Kumarasinghe AP, de Boer B, Bateman AC, Kumarasinghe MP. DNA mismatch repair enzyme immunohistochemistry in colorectal cancer: a comparison of biopsy and resection material. Pathology. 2010;42:414-20.

68. Shia J, Stadler Z, Weiser MR, Rentz M, Gonen M, Tang LH, et al. Immunohistochemical staining for DNA mismatch repair proteins in intestinal tract carcinoma: how reliable are biopsy samples? Am J Surg Pathol. 2011;35:447-54.
69. Vilkin A, Leibovici-Weissman Y, Halpern M, Morgenstern S, Brazovski E, Gingold-Belfer R, et al. Immunohistochemistry staining for mismatch repair proteins: the endoscopic biopsy material provides useful and coherent results. Hum Pathol. 2015;46:1705-11.

70. Haraldsdottir S, Roth R, Pearlman R, Hampel H, Arnold CA, Frankel WL. Mismatch repair deficiency concordance between primary colorectal cancer and corresponding metastasis. Fam Cancer. 2016;15:253-60.

71. Sepulveda AR, Hamilton SR, Allegra CJ, Grody W, CushmanVokoun AM, Funkhouser WK, et al. Molecular Biomarkers for the Evaluation of Colorectal Cancer: Guideline From the American Society for Clinical Pathology, College of American Pathologists, Association for Molecular Pathology, and American Society of Clinical Oncology. Arch Pathol Lab Med 2017.

72. Roth RM, Haraldsdottir S, Hampel H, Arnold CA, Frankel WL. Discordant Mismatch Repair Protein Immunoreactivity in Lynch Syndrome-Associated Neoplasms: A Recommendation for Screening Synchronous/Metachronous Neoplasms. Am J Clin Pathol. 2016;146:50-6.

73. Bellizzi AM, Frankel WL. Colorectal cancer due to deficiency in DNA mismatch repair function: a review. Adv Anat Pathol. 2009;16:405-17.

74. Kalady MF, Kravochuck SE, Heald B, Burke CA, Church JM. Defining the adenoma burden in lynch syndrome. Dis Colon Rectum. 2015;58:388-92.

75. Walsh MD, Buchanan DD, Pearson SA, Clendenning M, Jenkins MA, Win AK, et al. Immunohistochemical testing of conventional adenomas for loss of expression of mismatch repair proteins in Lynch syndrome mutation carriers: a case series from the Australasian site of the colon cancer family registry. Mod Pathol. 2012;25:722-30.

76. Yurgelun MB, Goel A, Hornick JL, Sen A, Turgeon DK. Ruffin MTt, et al. Microsatellite instability and DNA mismatch repair protein deficiency in Lynch syndrome colorectal polyps. Cancer Prev Res (Phila). 2012;5:574-82.

77. Wong NA, Gonzalez D, Salto-Tellez M, Butler R, Diaz-Cano SJ, Ilyas M, et al. RAS testing of colorectal carcinoma-a guidance document from the Association of Clinical Pathologists Molecular Pathology and Diagnostics Group. Journal of clinical pathology. 2014;67:751-7.

78. Kircher SM, Mohindra N, Nimeiri H. Cost Estimates and Economic Implications of Expanded RAS Testing in Metastatic Colorectal Cancer. The Oncologist. 2015;20:14-8.

79. Tol J, Koopman M, Cats A, Rodenburg CJ, Creemers GJ, Schrama JG, et al. Chemotherapy, bevacizumab, and cetuximab in metastatic colorectal cancer. N Engl J Med. 2009;360:563-72.

80. Lievre A, Bachet JB, Boige V, Cayre A, Le Corre D, Buc E, et al. KRAS mutations as an independent prognostic factor in patients with advanced colorectal cancer treated with cetuximab. J Clin Oncol. 2008;26:374-9.

81. Amado RG, Wolf M, Peeters M, Van Cutsem E, Siena S, Freeman DJ, et al. Wild-type KRAS is required for panitumumab efficacy in patients with metastatic colorectal cancer. J Clin Oncol. 2008;26:1626-34.

82. Douillard JY, Oliner KS, Siena S, Tabernero J, Burkes R, Barugel M, et al. Panitumumab-FOLFOX4 treatment and RAS mutations in colorectal cancer. N Engl J Med. 2013; 369:1023-34.

83. Douillard JY, Rong A, Sidhu R. RAS mutations in colorectal cancer. N Engl J Med. 2013;369:2159-60.

84. Network NCC. NCCN clinical practice guidelines in oncology: colon cancer (Version 2.2018). Available at: https://www.nccn. org/professionals/physician_gls/pdf/colon.pdf Accessed June 17, 2018. 2018. 
85. Rajagopalan H, Bardelli A, Lengauer C, Kinzler KW, Vogelstein B, Velculescu VE. Tumorigenesis: RAF/RAS oncogenes and mismatch-repair status. Nature. 2002; 418:934.

86. Ogino S, Shima K, Meyerhardt JA, McCleary NJ, Ng K, Hollis D, et al. Predictive and prognostic roles of BRAF mutation in stage III colon cancer: results from intergroup trial CALGB 89803. Clin Cancer Res. 2012;18:890-900.

87. Laurent-Puig P, Cayre A, Manceau G, Buc E, Bachet JB, Lecomte T, et al. Analysis of PTEN, BRAF, and EGFR status in determining benefit from cetuximab therapy in wild-type KRAS metastatic colon cancer. J Clin Oncol. 2009;27:5924-30.

88. Di Nicolantonio F, Martini M, Molinari F, Sartore-Bianchi A, Arena S, Saletti $\mathrm{P}$, et al. Wild-type BRAF is required for response to panitumumab or cetuximab in metastatic colorectal cancer. J Clin Oncol. 2008;26:5705-12.

89. Bokemeyer C, Van Cutsem E, Rougier P, Ciardiello F, Heeger S, Schlichting M, et al. Addition of cetuximab to chemotherapy as first-line treatment for KRAS wild-type metastatic colorectal cancer: pooled analysis of the CRYSTAL and OPUS randomised clinical trials. European journal of cancer (Oxford, England: 1990). 2012;48:1466-75.

90. Pietrantonio F, Petrelli F, Coinu A, Di Bartolomeo M, Borgonovo $\mathrm{K}$, Maggi $\mathrm{C}$, et al. Predictive role of BRAF mutations in patients with advanced colorectal cancer receiving cetuximab and panitumumab: a meta-analysis. European journal of cancer (Oxford, England: 1990). 2015;51:587-94.

91. Rowland A, Dias MM, Wiese MD, Kichenadasse G, McKinnon RA, Karapetis CS, et al. Meta-analysis of BRAF mutation as a predictive biomarker of benefit from anti-EGFR monoclonal antibody therapy for RAS wild-type metastatic colorectal cancer. Br J Cancer. 2015;112:1888-94.

92. Vakiani E. Molecular Testing of Colorectal Cancer in the Modern Era: What Are We Doing and Why? Surg Pathol Clin. 2017;10:1009-20.

93. Martin V, Landi L, Molinari F, Fountzilas G, Geva R, Riva A, et al. HER2 gene copy number status may influence clinical efficacy to anti-EGFR monoclonal antibodies in metastatic colorectal cancer patients. Br J Cancer. 2013;108:668-75.

94. Sartore-Bianchi A, Trusolino L, Martino C, Bencardino K, Lonardi S, Bergamo F, et al. Dual-targeted therapy with trastuzumab and lapatinib in treatment-refractory, $<\mathrm{em}>\mathrm{KRAS}</ \mathrm{em}>$ codon 12/13 wild-type, HER2-positive metastatic colorectal cancer (HERACLES): a proof-of-concept, multicentre, openlabel, phase 2 trial. The Lancet Oncology. 2016;17:738-46.

95. Hampel H, Pearlman R, Beightol M, et al. Assessment of tumor sequencing as a replacement for lynch syndrome screening and current molecular tests for patients with colorectal cancer. JAMA oncology 2018.

96. Gallego CJ, Shirts BH, Bennette CS, Guzauskas G, Amendola LM, Horike-Pyne M, et al. Next-Generation Sequencing Panels for the Diagnosis of Colorectal Cancer and Polyposis Syndromes: A Cost-Effectiveness Analysis. J Clin Oncol. 2015;33:2084-91.

97. Pearlman R, Frankel WL, Swanson B, Zhao W, Yilmaz A, Miller K, et al. Prevalence and Spectrum of Germline Cancer Susceptibility Gene Mutations Among Patients With Early-Onset Colorectal Cancer. JAMA oncology 2016.

98. Gray PN, Tsai P, Chen D, Wu S, Hoo J, Mu W, et al. TumorNext-Lynch-MMR: a comprehensive next generation sequencing assay for the detection of germline and somatic mutations in genes associated with mismatch repair deficiency and Lynch syndrome. Oncotarget. 2018;9:20304-22.

99. Zarkavelis G, Boussios S, Papadaki A, Katsanos KH, Christodoulou DK, Pentheroudakis G. Current and future biomarkers in colorectal cancer. Annals of gastroenterology. 2017;30:613-21.

100. Khakoo S, Georgiou A, Gerlinger M, Cunningham D, Starling N. Circulating tumour DNA, a promising biomarker for the management of colorectal cancer. Critical reviews in oncology/ hematology. 2018;122:72-82.

101. Moati E, Taly V, Didelot A, Perkins G, Blons H, Taieb J, et al. Role of circulating tumor DNA in the management of patients with colorectal cancer. Clinics and research in hepatology and gastroenterology 2018. 